\title{
An isotope dilution model for partitioning of phenylalanine and tyrosine uptake by the liver of lactating dairy cows
}

Article

Accepted Version

Creative Commons: Attribution-Noncommercial-No Derivative Works 4.0

Crompton, L. A., McKnight, L. L., Reynolds, C. K., Mills, J. A. N., Ellis, J. L., Hanigan, M. D., Dijkstra, J., Bequette, B. J., Bannink, A. and France, J. (2018) An isotope dilution model for partitioning of phenylalanine and tyrosine uptake by the liver of lactating dairy cows. Journal of Theoretical Biology, 444. pp. 100-107. ISSN 0022-5193 doi:

https://doi.org/10.1016/j.jtbi.2017.12.016 Available at https://centaur.reading.ac.uk/74567/

It is advisable to refer to the publisher's version if you intend to cite from the work. See Guidance on citing.

To link to this article DOI: http://dx.doi.org/10.1016/j.jtbi.2017.12.016

Publisher: Elsevier

All outputs in CentAUR are protected by Intellectual Property Rights law, including copyright law. Copyright and IPR is retained by the creators or other copyright holders. Terms and conditions for use of this material are defined in the End User Agreement. 


\section{CentAUR}

Central Archive at the University of Reading

Reading's research outputs online 
1 An isotope dilution model for partitioning of phenylalanine and tyrosine uptake by the liver of lactating dairy cows

L.A. Crompton ${ }^{\mathrm{a},{ }^{*}}$, L.L. McKnight ${ }^{\mathrm{b}}$, C.K. Reynolds ${ }^{\mathrm{a}}$, J.A.N. Mills ${ }^{\mathrm{a}}$, J.L. Ellis ${ }^{\mathrm{b}, \mathrm{c}}$, M.D.

a Sustainable Agriculture and Food Systems Research Division, School of Agriculture, Policy and Development, University of Reading, Whiteknights, Reading RG6 6AR, UK

${ }^{\mathrm{b}}$ Centre for Nutrition Modelling, Department of Animal Biosciences, University of Guelph, Ontario N1G 2W1, Canada

$11{ }^{\mathrm{c}}$ Animal Nutrition Group, Wageningen University \& Research, 6700 AH Wageningen, The Netherlands

${ }^{\mathrm{d}}$ Department of Dairy Science, Virginia Tech, 2080 Litton Reaves, Blacksburg, VA 24061,

\section{USA}

15 e Department of Animal \& Avian Sciences, University of Maryland, College Park, MD 20742, USA

${ }^{1}$ Deceased

19

*Corresponding author: 1.a.crompton@reading.ac.uk (L.A. Crompton) 


\section{Abstract}

22 An isotope dilution model to describe the partitioning of phenylalanine (PHE) and tyrosine

23 (TYR) in the bovine liver was developed. The model comprises four intracellular and six

24 extracellular pools and various flows connecting these pools and external blood.

25 Conservation of mass principles were applied to generate the fundamental equations

26 describing the behaviour of the system in the steady state. The model was applied to datasets

27 from multi-catheterised dairy cattle during a constant infusion of $\left[1-{ }^{13} \mathrm{C}\right]$ phenylalanine and

$28\left[2,3,5,6-{ }^{2} \mathrm{H}\right]$ tyrosine tracers. Model solutions described the extraction of PHE and TYR from

29 the liver via the portal vein and hepatic artery. In addition, the exchange of free PHE and

30 TYR between extracellular and intracellular pools was explained and the hydroxylation of

31 PHE to TYR was estimated. The model was effective in providing information about the

32 fates of PHE and TYR in the liver and could be used as part of a more complex system

33 describing amino acid metabolism in the whole animal.

34

35 Keywords:

36 Isotope dilution, Kinetic model, Liver, Phenylalanine, Tyrosine 


\section{Introduction}

In ruminant production, the efficiency of milk protein synthesis from absorbed dietary nitrogen is quite low, 25-35 \% (Hristov et al., 2004). In addition to the economic burden on the producer, urinary nitrogen losses contribute to greenhouse gas emissions and waterway contamination (Dijkstra et al., 2013). Milk protein synthesis is sensitive to essential amino acid supply, particularly phenylalanine (PHE). In vivo studies have demonstrated a reduction in milk protein concentrations when PHE is in low dietary supply (Rulquin and Pisulewski, 2000) and/or deficient in infusion mixtures (Doelman et al., 2015; Doepel et al., 2016). In the post-absorptive state, the liver has a key role in regulating PHE homeostasis. The liver can regulate the provision of PHE to peripheral tissues including the mammary gland, and remove PHE not used by the mammary gland or other peripheral tissues.

Net flux of PHE across the bovine liver has been examined in vivo using the arteriovenous difference technique (Tagari et al., 2004, 2008; Raggio et al., 2007; Berthiaume et al., 2006; Cantalapiedra-Hijar et al., 2014; Larsen et al., 2015). These studies reported a negative net flux of PHE, suggesting the liver is a major site of PHE utilization. In general, PHE has two metabolic fates, incorporation into protein or conversion to tyrosine (TYR) via PHE hydroxylase (oxidation). As a result, PHE catabolism always follows the pathway of TYR catabolism. Therefore, to examine PHE metabolism experimentally the simultaneous infusion of PHE and TYR stable isotope tracers is preferred. To resolve the kinetic data from such isotope infusion studies, mathematical models must be applied. Mathematical models to describe PHE kinetics have varied in complexity (reviewed by Matthews, 2007). Simple models ignore the hydroxylation of PHE to TYR, whereas, more complex models aim to explain PHE conversion to TYR. In our previous publication

61 (Crompton et al., 2014), we presented an eight pool compartmental model describing PHE 
progression of this work and our previous model of leucine metabolism in the bovine liver

64 (France et al., 1998). The primary objective was to develop a steady state model of hepatic PHE and TYR metabolism. The new model describes the partitioning of the PHE and TYR between constitutive and export protein synthesis and potential other metabolic fates such as hydroxylation of PHE to TYR.

68

2. The model

The scheme adopted is shown in Figure 1a. It contains four intracellular and six extracellular pools. The intracellular pools are free PHE (pool 6), PHE in export protein (pool 5), free TYR (pool 7) and TYR in export protein (pool 8), while the extracellular ones represent portal vein PHE and TYR (pools 1 and 3), hepatic artery PHE and TYR (pools 2 and 4) and venous PHE and TYR (pools 9 and X). Pools external to the model and therefore not specifically represented are indicated by the digit zero. The flows of PHE and TYR between pools and into and out of the system are shown as arrowed lines.

The export protein-bound PHE pool has a single inflow: from free PHE, $F_{56}$, and two efflows: secretion of export protein, $F_{05}$, and degradation, $F_{65}$. The intracellular free PHE pool has four inflows: from the degradation of constitutive liver protein, $F_{60}$, from the extracellular portal vein pool, $F_{61}$, from the hepatic artery pool, $F_{62}$, and from degradation of export protein, $F_{65}$. The pool has four efflows: synthesis of constitutive liver protein, $F_{06}$, incorporation into export protein, $F_{56}$, hydroxylation to the intracellular free TYR pool, $F_{76}$, and outflow to the extracellular hepatic vein PHE pool, $F_{96}$. The intracellular free TYR pool has five inflows: from the degradation of constitutive liver protein, $F_{70}$, from the extracellular portal vein TYR pool, $F_{73}$, from the hepatic artery TYR pool, $F_{74}$, from the intracellular PHE pool, $F_{76}$, and from the degradation of export protein, $F_{78}$. The pool has four efflows:

87 oxidation and TYR degradation products, $F_{07}^{(o)}$, synthesis of constitutive liver protein, $F_{07}^{(s)}$, 
incorporation into export protein, $F_{87}$, and outflow to the extracellular hepatic vein TYR pool, $F_{\mathrm{X} 7}$. The export protein-bound TYR pool has one inflow: from the intracellular free TYR pool, $F_{87}$, and two efflows: secretion of export protein, $F_{08}$, and degradation, $F_{78}$.

The extracellular portal vein PHE pool has a single inflow: entry into the pool, $F_{10}$, and two efflows: uptake by the liver, $F_{61}$, and bypass to the extracellular hepatic vein PHE pool, $F_{91}$. The extracellular hepatic artery PHE pool has a single inflow: entry into the pool, $F_{20}$, and two efflows: uptake by the liver, $F_{62}$, and bypass to the extracellular hepatic vein PHE pool, $F_{92}$. The same description applies to the corresponding TYR pools, i.e. pools 3 and 4 with flows $F_{30}, F_{73}, F_{\mathrm{X} 3}, F_{40}, F_{74}$, and $F_{\mathrm{X} 4}$, respectively. The extracellular hepatic vein PHE pool has three inflows: bypass from the portal vein PHE pool, $F_{91}$, bypass from the hepatic artery PHE pool, $F_{92}$, and release from the intracellular PHE pool, $F_{96}$, and one efflow from the system, $F_{09}$. The same description applies to the corresponding TYR pool with flows $F_{\mathrm{X} 3}$, $F_{\mathrm{X} 4}, F_{\mathrm{X} 7}$, and $F_{0 \mathrm{X}}$ respectively.

The schemes adopted for the movement of label are shown in Figures 1b and 1c. Labelled $\left[1-{ }^{13} \mathrm{C}\right] \mathrm{PHE}$ and $\left[2,3,5,6-{ }^{2} \mathrm{H}\right] \mathrm{TYR}$ were infused into the jugular vein at a constant rate for $8 \mathrm{~h}$. . The enrichments of the extracellular pools are measured directly by taking blood samples from the portal vein, hepatic artery and hepatic vein during the isotope infusion. The enrichments of the intracellular pools can only be measured directly using invasive procedures and to avoid such procedures, the enrichments of the intracellular pools were set as a prescribed fraction of the corresponding arterial enrichment in this study. Blood flow rate across the liver is measured by downstream dye dilution using para-amino hippuric acid (PAH), but uncorrected for any N-acetylation that occurs across the liver (Katz and Bergman, 1969). The scheme assumes that the only entry of label into the system is into the PHE and TYR portal vein and hepatic artery pools via the effective infusion rates, flows $I_{1}$, 
$112 I_{2}, I_{3}, \Phi_{3}, I_{4}$, and $\Phi_{4}$ and that the duration of the infusion is such that no label arises from the

113 breakdown of constitutive protein.

114 Conservation of mass principles can be applied to each pool in Figure 1a, b, c to generate

115 differential equations that describe the dynamic behaviour of the system. For total (isotopic

116 plus non-isotopic) PHE and TYR, these fundamental equations are (mathematical notation is

117 defined in Table 1):

$118 \quad \frac{\mathrm{d} Q_{1}}{\mathrm{~d} t}=F_{10}-F_{61}-F_{91}$

119

$$
\frac{\mathrm{d} Q_{2}}{\mathrm{~d} t}=F_{20}-F_{62}-F_{92}
$$

120

$$
\frac{\mathrm{d} Q_{3}}{\mathrm{~d} t}=F_{30}-F_{73}-F_{\mathrm{X} 3}
$$

121

$$
\frac{\mathrm{d} Q_{4}}{\mathrm{~d} t}=F_{40}-F_{74}-F_{\mathrm{X} 4}
$$

122

$$
\frac{\mathrm{d} Q_{5}}{\mathrm{~d} t}=F_{56}-F_{05}-F_{65}
$$

123

$$
\frac{\mathrm{d} Q_{6}}{\mathrm{~d} t}=F_{60}+F_{61}+F_{62}+F_{65}-F_{06}-F_{56}-F_{76}-F_{96}
$$

$$
\frac{\mathrm{d} Q_{7}}{\mathrm{~d} t}=F_{70}+F_{73}+F_{74}+F_{76}+F_{78}-F_{07}^{(o)}-F_{07}^{(s)}-F_{87}-F_{\mathrm{X} 7}
$$

125

$$
\frac{\mathrm{d} Q_{8}}{\mathrm{~d} t}=F_{87}-F_{08}-F_{78}
$$

126

$$
\frac{\mathrm{d} Q_{9}}{\mathrm{~d} t}=F_{91}+F_{92}+F_{96}-F_{09}
$$

$$
\frac{\mathrm{d} Q_{\mathrm{X}}}{\mathrm{d} t}=F_{\mathrm{X} 3}+F_{\mathrm{X} 4}+F_{\mathrm{X} 7}-F_{0 \mathrm{X}}
$$

128 and for $\left[{ }^{13} \mathrm{C}\right]$ labelled PHE and TYR:

129

$$
\frac{\mathrm{d} q_{1}}{\mathrm{~d} t}=I_{1}-e_{1}\left(F_{61}+F_{91}\right)
$$


$130 \quad \frac{\mathrm{d} q_{2}}{\mathrm{~d} t}=I_{2}-e_{2}\left(F_{62}+F_{92}\right)$

$131 \quad \frac{\mathrm{d} q_{3}}{\mathrm{~d} t}=I_{3}-e_{3}\left(F_{73}+F_{\mathrm{X} 3}\right)$

$132 \quad \frac{\mathrm{d} q_{4}}{\mathrm{~d} t}=I_{4}-e_{4}\left(F_{74}+F_{\mathrm{X} 4}\right)$

$133 \quad \frac{\mathrm{d} q_{5}}{\mathrm{~d} t}=e_{6} F_{56}-e_{5}\left(F_{05}+F_{65}\right)$

134

$\frac{\mathrm{d} q_{6}}{\mathrm{~d} t}=e_{1} F_{61}+e_{2} F_{62}+e_{5} F_{65}-e_{6}\left(F_{06}+F_{56}+F_{76}+F_{96}\right)$

135

$\frac{\mathrm{d} q_{7}}{\mathrm{~d} t}=e_{3} F_{73}+e_{4} F_{74}+e_{6} F_{76}+e_{8} F_{78}-e_{7}\left(F_{07}^{(o)}+F_{07}^{(s)}+F_{87}+F_{\mathrm{X} 7}\right)$

$136 \quad \frac{\mathrm{d} q_{8}}{\mathrm{~d} t}=e_{7} F_{87}-e_{8}\left(F_{08}+F_{78}\right)$

$137 \quad \frac{\mathrm{d} q_{9}}{\mathrm{~d} t}=e_{1} F_{91}+e_{2} F_{92}+e_{6} F_{96}-e_{9} F_{09}$

138

$139 \quad \frac{\mathrm{d} q_{\mathrm{X}}}{\mathrm{d} t}=e_{3} F_{\mathrm{X} 3}+e_{4} F_{\mathrm{X} 4}+e_{7} F_{\mathrm{X} 7}-e_{\mathrm{X}} F_{0 \mathrm{X}}$

140 and for $\left[{ }^{2} \mathrm{H}\right]$ labelled TYR:

141

$$
\frac{\mathrm{d} \phi_{3}}{\mathrm{~d} t}=\Phi_{3}-\varepsilon_{3}\left(F_{73}+F_{\mathrm{X} 3}\right)
$$

142

(21)

143

$$
\frac{\mathrm{d} \phi_{4}}{\mathrm{~d} t}=\Phi_{4}-\varepsilon_{4}\left(F_{74}+F_{\mathrm{X} 4}\right)
$$

144

$$
\frac{\mathrm{d} \phi_{7}}{\mathrm{~d} t}=\varepsilon_{3} F_{73}+\varepsilon_{4} F_{74}+\varepsilon_{8} F_{78}-\varepsilon_{7}\left(F_{07}^{(o)}+F_{07}^{(s)}+F_{87}+F_{\mathrm{X} 7}\right)
$$

145

$$
\frac{\mathrm{d} \phi_{8}}{\mathrm{~d} t}=\varepsilon_{7} F_{87}-\varepsilon_{8}\left(F_{08}+F_{78}\right)
$$

$$
\frac{\mathrm{d} \phi_{\mathrm{X}}}{\mathrm{d} t}=\varepsilon_{3} F_{\mathrm{X} 3}+\varepsilon_{4} F_{\mathrm{X} 4}+\varepsilon_{7} F_{\mathrm{X} 7}-\varepsilon_{\mathrm{X}} F_{0 \mathrm{X}}
$$


When the system is in steady state with respect to both total and labelled PHE and TYR,

148 the derivative terms in equations (1)-(25) are zero. For the scheme assumed, the enrichment

149 of intracellular export protein-bound pools equalizes with that of the respective free pool in

150 steady state (i.e. $e_{5}=e_{6}, e_{8}=e_{7}, \varepsilon_{8}=\varepsilon_{7}$ ) otherwise equations (5) and (15), and (8), (18) and

151 (24) are inconsistent. It should be noted that the liver is a heterogeneous mixture of cells, and

152 enrichment may differ at different parts of the organ where synthesis of export protein or

153 synthesis of constitutive protein takes place. Within cells there are different sites of synthesis

154 and oxidation, and differences in the sites of synthesis of individual proteins, with labelling of

155 the tracer amino acid highest at points near the cell surface and lowest at points near the sites

156 of degradation (see Waterlow, 2006). After equating intracellular enrichments and

157 eliminating redundant equations etc., equations (11) to (25) yield the following useful

158 identities:

159

160

161

162

163

164

$$
I_{1}-e_{1}\left(F_{61}+F_{91}\right)=0
$$

$$
I_{2}-e_{2}\left(F_{62}+F_{92}\right)=0
$$

(1)

$$
e_{1} F_{61}+e_{2} F_{62}-e_{6}\left(F_{06}+F_{56}+F_{76}+F_{96}-F_{65}\right)=0
$$

$e_{3} F_{\mathrm{X} 3}+e_{4} F_{\mathrm{X} 4}+e_{7} F_{\mathrm{X} 7}-e_{\mathrm{X}} F_{0 \mathrm{X}}=0$

165

$$
e_{3} F_{73}+e_{4} F_{74}+e_{6} F_{76}-e_{7}\left(F_{07}^{(o)}+F_{07}^{(s)}+F_{87}+F_{\mathrm{X} 7}-F_{78}\right)=0
$$

$$
e_{1} F_{91}+e_{2} F_{92}+e_{6} F_{96}-e_{9} F_{09}=0
$$

$$
\Phi_{3}-\varepsilon_{3}\left(F_{73}+F_{\mathrm{X} 3}\right)=0
$$

167

$$
\Phi_{4}-\varepsilon_{4}\left(F_{74}+F_{\mathrm{X} 4}\right)=0
$$

$$
\varepsilon_{3} F_{73}+\varepsilon_{4} F_{74}-\varepsilon_{7}\left(F_{07}^{(o)}+F_{07}^{(s)}+F_{87}+F_{X 7}-F_{78}\right)=0
$$



in export protein, $\mathrm{CO}_{2}$ production and PHE and TYR removal from the hepatic vein pools

171 (i.e. $F_{05}, F_{08}, F_{07}^{(o)}, F_{09}$ and $F_{0 X}$, respectively) can all be measured experimentally. Further, it

172 is mathematically convenient to assume that percentage PHE extraction by the liver is the

173 same from the portal vein and hepatic artery supplies, giving:

174

$$
\frac{F_{91}}{F_{92}}\left(=\frac{F_{61}}{F_{62}}\right)=\frac{F_{10}}{F_{20}}
$$
with equations (26)-(36), gives the following unique solution:

177

$$
F_{10}=I_{1} / e_{1}
$$

178

$$
F_{20}=I_{2} / e_{2}
$$

$$
F_{30}=\Phi_{3} / \varepsilon_{3}
$$

$$
F_{40}=\Phi_{4} / \varepsilon_{4}
$$

$$
\overline{F_{56}-F_{65}}=\widetilde{F}_{05}
$$

$$
\overline{F_{87}-F_{78}}=\widetilde{F}_{08}
$$

$$
F_{\mathrm{X} 7}=\frac{\left(e_{4}-e_{3}\right)\left(\varepsilon_{X}-\varepsilon_{3}\right)-\left(e_{X}-e_{3}\right)\left(\varepsilon_{4}-\varepsilon_{3}\right)}{\left(e_{4}-e_{3}\right)\left(\varepsilon_{7}-\varepsilon_{3}\right)-\left(e_{7}-e_{3}\right)\left(\varepsilon_{4}-\varepsilon_{3}\right)} \widetilde{F}_{0 \mathrm{X}}
$$

$$
F_{\mathrm{X} 4}=\frac{\left(\varepsilon_{X}-\varepsilon_{3}\right) \widetilde{F}_{0 \mathrm{X}}-\left(\varepsilon_{7}-\varepsilon_{3}\right) F_{\mathrm{X} 7}}{\left(\varepsilon_{4}-\varepsilon_{3}\right)}
$$

$$
F_{\mathrm{X} 3}=\widetilde{F}_{0 \mathrm{X}}-F_{\mathrm{X} 4}-F_{\mathrm{X} 7}
$$

$$
F_{73}=F_{30}-F_{\mathrm{X} 3}
$$

187

$$
F_{74}=F_{40}-F_{\mathrm{X} 4}
$$

188

$$
F_{07}^{(s)}=\frac{\varepsilon_{3}}{\varepsilon_{7}} F_{73}+\frac{\varepsilon_{4}}{\varepsilon_{7}} F_{74}-\widetilde{F}_{07}^{(o)}-\overline{F_{87}-F_{78}}-F_{\mathrm{X} 7}
$$




$$
F_{76}=\frac{e_{7}}{e_{6}}\left(\widetilde{F}_{07}^{(o)}+F_{07}^{(s)}+\overline{F_{87}-F_{78}}+F_{\mathrm{X} 7}\right)-\frac{e_{3}}{e_{6}} F_{73}-\frac{e_{4}}{e_{6}} F_{74}
$$

$$
F_{70}=\widetilde{F}_{07}^{(o)}+F_{07}^{(s)}+\overline{F_{87}-F_{78}}+F_{\mathrm{X} 7}-F_{73}-F_{74}-F_{76}
$$

$$
F_{91}=\frac{\left(e_{9}-e_{6}\right) \widetilde{F}_{09}}{\left(e_{1}-e_{6}\right)+\left(e_{2}-e_{6}\right) \frac{F_{20}}{F_{10}}}
$$

192

$$
F_{92}=\frac{F_{20}}{F_{10}} F_{91}
$$

193

$$
F_{96}=\widetilde{F}_{09}-F_{91}-F_{92}
$$

194

$$
F_{61}=F_{10}-F_{91}
$$

195

$$
F_{62}=F_{20}-F_{92}
$$

$$
F_{06}=\frac{e_{1}}{e_{6}} F_{61}+\frac{e_{2}}{e_{6}} F_{62}-\overline{F_{56}-F_{65}}-F_{76}-F_{96}
$$

$$
F_{60}=F_{06}+\overline{F_{56}-F_{65}}+F_{76}+F_{96}-F_{61}-F_{62}
$$

where for these equations the italics denote steady state values of flows and enrichments, the

tilde identifies a measured flow, and the over-lining (not to be confused with statistical mean)

(37)-(57) were obtained through analytical solution (solving by hand) using conventional

202 linear algebra.

\section{Application}

Application of the model is illustrated using data from an experiment conducted in the

UK at the University of Reading with multi-catheterised mid-lactation Holstein-Friesian dairy cows (average live-weight $667 \mathrm{~kg}$ ). Animals were fed hourly by auto-feeders total mixed ration (TMR) diets consisting of a 50:50 mixture on a dry matter basis of forage and concentrate with the forage comprised of grass silage and chopped dried Lucerne in a 25:75 
210 ratio on a dry matter basis. Concentrates were formulated to provide crude protein levels of 211 approximately 110 and 200 g per kg concentrate dry matter, such that average TMR crude 212 protein concentrations were 128 and $175 \mathrm{~g} / \mathrm{kg}$ dry matter. Average daily dry matter intake 213 and milk yield for these animals were $22 \mathrm{~kg} / \mathrm{d}$ and $30 \mathrm{~L} / \mathrm{d}$, respectively. The cows were given 214 constant abomasal infusions of water $(18 \mathrm{~L} / \mathrm{d})$ for $4 \mathrm{~d}$, followed by a buffered mixture of 215 essential amino acids for a further $6 \mathrm{~d}$. The essential amino acids were administered at a 216 daily rate equivalent to the essential amino acids in $800 \mathrm{~g}$ milk protein. On the final day of 217 each abomasal infusion, animals received a primed, continuous infusion at a constant rate 218 into the jugular vein of $\left[1-{ }^{13} \mathrm{C}\right] \mathrm{PHE}(350 \mathrm{mg} / \mathrm{h})$ and $\left[2,3,5,6-{ }^{2} \mathrm{H}\right] \mathrm{TYR}(100 \mathrm{mg} / \mathrm{h})$ in sterile 219 saline for $8 \mathrm{~h}$. Blood samples were taken simultaneously from catheters in the dorsal aorta and the portal and hepatic veins at hourly intervals for the duration of the infusion for the measurement of blood flow rate (by PAH dilution) and nutrient metabolism by the portal drained viscera and liver. The final four blood samples taken 5-8 h after the infusion started were averaged to provide steady state values.

The relevant experimental measurements are given in Table 2. They are reported for three animals during the water infusion (2 low protein; 1 high protein diet) and one animal during the amino acid infusion (high protein diet). Values are based on plasma rather than whole blood. Phenylalanine and TYR measurements are based on free rather than total (i.e. free plus bound) plasma PHE and TYR. The effective isotope infusion rates to the liver, $I_{1}$, $I_{2}$, and $I_{3}, \Phi_{3}, I_{4}, \Phi_{4}$ were obtained from portal vein and arterial concentration and enrichment of PHE and TYR and plasma flow rate in the portal vein and hepatic artery. The flows $F_{09}$ and $F_{0 X}$ were determined from hepatic vein PHE and TYR concentration and plasma flow rate in the hepatic vein. The intracellular enrichments $e_{6}, e_{7}$ and $\varepsilon_{7}$ and the flows $F_{05}, F_{08}$ were not measured in the trial and had to be prescribed. Unpublished observations from our laboratories demonstrated an intracellular to extracellular enrichment ratio of 0.3 for PHE and 
TYR. Therefore, the missing intracellular free PHE and TYR enrichments, $e_{6}, e_{7}$, and $\varepsilon_{7}$ were initially calculated as 0.3 times the corresponding arterial enrichments $e_{2}, e_{4}$, and $\varepsilon_{4}$ respectively. The export protein flows $F_{05}$ and $F_{08}$ were assigned values of $33.8 \mu \mathrm{mol} / \mathrm{min}$ and $25.0 \mu \mathrm{mol} / \mathrm{min}$ respectively based on Raggio et al. (2007) and the relative proportion of PHE and TYR in bovine serum albumin as a representative export protein (UniProt, 2017). The flow $F_{07}^{(o)}$ was obtained from labelled $\mathrm{CO}_{2}$ elevation in plasma flow across the liver and hepatic vein PHE enrichment in sheep (Harris et al., 1992). comprehensive statistical analysis; therefore the results must be interpreted with a degree of caution. Initial solutions for each cow were non-physiological as some of the derived flows gave negative values. Therefore, error bands of $\pm 25 \%$ were placed around the values given in Table 2 of the prescribed intracellular enrichments $\left(e_{6}, e_{7}\right.$ and $\left.\varepsilon_{7}\right)$ and the measured extracellular enrichments close to minimum detection levels $\left(e_{3}, e_{4}\right.$ and $\left.e_{\mathrm{X}}\right)$, and the solution space mapped out by these bands was searched to find the best feasible solution for each cow. The best feasible solution was obtained by sum of squares minimisation, where the sum of squares to be minimised (SS) was defined as

$$
\mathrm{SS}=\left(1-\frac{F_{60}}{F_{06}}\right)^{2}+\left(1-\frac{F_{70}}{F_{07}^{(s)}}\right)^{2}+\left(\frac{F_{07}^{(s)}}{F_{06}}-\frac{F_{70}}{F_{60}}\right)^{2}
$$

The assumptions underlying SS are constitutive liver protein synthesis and degradation are moving towards equilibrium (as the cows were in mid-lactation), and the TYR to PHE ratio is the same (or similar) in synthesised and degraded liver tissue. If no feasible solution could be found, the error bands were expanded (up to $\pm 40 \%$ ) and the search repeated. The final solutions are shown in Table 3.

An analysis of measurement errors in experimental enrichments and infusion rates on model solutions was conducted. Mean values across all datasets were assigned to $e_{1}, e_{2}, e_{3}$, 
$e_{4}, e_{6}, e_{7}, e_{9}, e_{\mathrm{X}}, \varepsilon_{3}, \varepsilon_{4}, \varepsilon_{7}, \varepsilon_{\mathrm{X}}, I_{1}, I_{2}, \Phi_{3}, \Phi_{4}, F_{05}, F_{07}^{(o)}, F_{08}, F_{09}, F_{0 \mathrm{X}}$. Inputs were then perturbed

260 in turn by $0, \pm 10 \%$ and $\pm 20 \%$. Each calculated flow $(y, \mu \mathrm{mol} / \mathrm{min})$ was then plotted against

261 the perturbation ( $x, \%)$, and a five-point linear regression of $y$ on $x$ performed to determine

262 the slope of the line produced. The average slope was subsequently scaled by its corresponding unperturbed average flow value, giving the scaled slopes dimensions of \% change in $y$ per \% change in $x$. Results of the error assessment are presented in Table 4. In general, errors in infusion rates and measured flows had little impact on the sensitivity of model solutions. However, errors in the measurement of isotopic enrichment and in assumed intracellular enrichment values, cause marked changes in calculated flows, emphasising the value of measuring intracellular enrichment directly.

\section{Discussion}

Improving nitrogen utilization in the ruminant, and consequently minimizing the environmental impacts of ruminant production, is dependent on a clear understanding of postabsorptive amino acid metabolism. The present model described the partitioning of the indispensable amino acid, PHE (and TYR), in the bovine liver. The model gave estimates of PHE flow across the liver, rates of PHE and TYR incorporation into constitutive and export protein synthesis, and the rate of hydroxylation of PHE to TYR.

PHE and TYR enter the liver via the portal vein and hepatic artery. Amino acids entering via the portal vein, the main blood supply to liver, represent recently absorbed or released amino acids from the portal drained viscera and recirculating amino acids coming 280 from the mesenteric and hepatic arteries. Incoming amino acids via arterial blood reflect the 281 utilization of nutrients by peripheral tissues (Reynolds, 2006). The model predicted a greater flow of PHE and TYR from the portal vein (90\% of total inflow) than that from the hepatic 
artery, which was expected as the portal vein accounted for the majority (84\%) of liver blood flow.

In vivo studies have observed a negative net flow of PHE across the bovine liver, suggesting the liver is a major site of catabolism (Tagari et al., 2004, 2008; Reynolds, 2006; Raggio et al., 2007; Berthiaume et al., 2006; Cantalapiedra-Hijar et al., 2014; Larsen et al., 2015). In agreement, model solutions indicated a net negative flow of PHE and TYR across the liver (efflow minus inflow, -396 and $-298 \mu \mathrm{mol} / \mathrm{min}$ PHE and TYR respectively). Other efflows of PHE and TYR from the liver included oxidation and incorporation into secreted hepatic proteins. Oxidation rates varied greatly in individual animals (range 146 to 525 $\mu \mathrm{mol} / \mathrm{min}$ ), the highest value observed in the animal receiving the essential amino acid 293 infusion. The range of oxidation rates in animals receiving the control water infusion were similar to those previously reported in lactating dairy cows (Raggio et al., 2007) fed low and high protein diets. Oxidation rates used in the present model represent the sum of PHE and TYR oxidation and combined PHE and TYR oxidation accounted for $23 \%$ of total PHE and TYR inflow to the liver. However, the current model enables the conversion of PHE to TYR to be estimated $\left(F_{76}\right)$ which enables the combined oxidation to be separated. Phenylalanine may either be used for protein synthesis or be converted to TYR which is catalysed by the enzyme phenylalanine hydroxylase and is the first and rate limiting step in the metabolic disposal of PHE. Tyrosine is then transaminated to $p$-hydroxyphenylpyruvate and ultimately

302 yields fumarate and acetoacetate, so that PHE and TYR give rise to both glucogenic and

303 ketogenic fragments. Tyrosine is not considered essential, because it can be synthesised from 304 PHE in addition to that provided from the diet. On average the model estimated that $23 \%$ of inflow of PHE from blood (sum of hepatic artery and portal vein inflows) to the liver was converted to TYR. Of the $178 \mu \mathrm{mol} / \mathrm{min}$ of PHE hydroxylated, $101 \mu \mathrm{mol} / \mathrm{min}$ were directly oxidised and $77 \mu \mathrm{mol} / \mathrm{min}$ contributed $11 \%$ of the $717 \mu \mathrm{mol} / \mathrm{min}$ total TYR inflow (sum of 
308 TYR from hepatic artery and portal vein and from PHE hydroxylation). Individual amino

309 acid oxidations as a percentage of liver inflow were estimated to be 13\% for PHE and 29\%

310 for TYR. Measuring TYR oxidation directly represents a challenge experimentally. In

311 general, deuterium labelled PHE is inadequate for quantifying PHE kinetics and oxidation,

312 which requires the use of carbon labelled PHE and by default, deuterium labelled TYR

313 (reviewed by Matthews, 2007).

314 Another efflow of PHE and TYR considered in the model was their incorporation into

315 hepatic export protein. The liver makes several export proteins of various functions.

316 Albumin is important for the maintenance of vascular osmotic pressure. Due to this critical

317 role, albumin synthesis is maintained across various mild physiological challenges, although

318 in more severe situations of nutrient shortage, albumin synthesis may decrease. Raggio et al.

319 (2007) determined export plasma protein synthesis rate in lactating dairy cows and assumed

320 that export plasma protein contained 5\% PHE. The value thus obtained by Raggio et al.

321 (2007) was used in the present model to represent the flow of PHE into export protein $\left(F_{05}\right)$.

322 Since plasma proteins are also derived from sources other than the liver, the assumption that

323 total plasma export protein synthesis is all hepatic in origin may well have overestimated the

324 flow of PHE into export protein to some degree in the current model. The incorporation of

325 TYR $\left(F_{08}\right)$ into albumin was unknown and assumed equivalent to that of PHE after correcting

326 for the relative proportions of PHE and TYR in albumin. This assumption is recognized as a

327 limitation of the current modelling exercise. Specifically, the incorporation of individual

328 amino acids depends on the type of export protein; some export proteins may require

329 proportionally higher amounts of PHE or TYR. This limitation was circumvented in our

330 bovine mammary model (Crompton et al., 2014) as the export protein was milk and isotope

331 enrichment in milk was easily measured. 

partitioning. Constitutive hepatic protein degradation was the largest contributor to the free PHE and TYR pools, followed by portal vein and hepatic artery delivery (PHE 72\%, 22\%, 6\%; TYR 65\%, 22\%, 5\%). It should be noted that these estimates are influenced by assumptions which had to be made with respect to intracellular enrichments, as discussed later. Flow of PHE and TYR into constitutive protein synthesis comprised $98 \%$ of total synthetic flow. The ratio of PHE to TYR in synthesised constitutive protein and degraded constitutive protein was the same in each animal (range 1.06 to 1.66) and averaged 1.30. The ratio of constitutive protein synthesis to degradation was 1.1 for both PHE and TYR. However, in mid to late lactation dairy cows, the ratio of PHE and TYR synthesis to degradation should be equal. Model estimates of intracellular PHE and TYR partitioning must be interpreted with caution due to methodological limitations and imposed assumptions.

344 For example, samples were taken from whole blood and free PHE and TYR concentrations were quantified and considered in the model. Therefore the extent to which peptide bound PHE and TYR contribute to constitutive protein synthesis and degradation flows cannot be determined. As hepatic tissues were not sampled, isotopic enrichment of the intracellular pools was estimated based on the sampled precursor pools. The choice of precursor pool enrichment is central in the present model as with any measurement of protein synthetic rate in the whole body or tissues (see Waterlow, 2006). The assumption that intracellular enrichments were 0.30 of plasma was based on unpublished observations from an unrelated in vivo trial from our laboratory. Using the same isotopes as the present study, average liver homogenate free enrichment for PHE and TYR was 0.30 (SD 0.07; range 0.19-0.38) of plasma enrichment in lactating dairy cattle. Initially, the model solved to give some nonphysiological flows and had to be re-solved by adjusting the intracellular enrichments and the extracellular ones close to minimum detection levels using a least-squares minimisation 
routine. Besides, the actual precursor pool for various constitutive and export proteins may

358

359

360

361

362

363

364

365

366

367

368

369

370

371

372

373

374

375

376

377

378

379

380

381

differ. The lack of homogeneity in activity at various parts of the liver indicates that

intracellular enrichment is not uniform throughout the liver, and enrichment in export protein and constitutive protein therefore may differ. In particular, the precursor enrichment for constitutive protein synthesis may be lower than that for export protein synthesis (Connell et al., 1997). Due to lack of specific measurements, this observation could not be included in the present model.

Another means of estimating intracellular enrichment would be to measure the incorporation of label into proteins having a fast turnover rate in plasma. For example, studies in humans use plasma VLDL apolipoprotein-B (Apo-B) enrichment as a hepatic intracellular marker protein (Rafi et al., 2008). However, to our knowledge this approach has not been undertaken in lactating dairy cattle and would likely yield the enrichment of the precursor pool used for export protein synthesis, which is not necessarily the same as the precursor pool for constitutive protein synthesis as discussed above.

\section{Conclusions}

The present 10-pool model allows for quantitative interpretation of the metabolism of PHE and TYR in the liver of dairy cattle by showing their partition among different fates. The model builds upon the existing eight pool model to describe protein turnover in the mammary gland of the lactating dairy cow (Crompton et al., 2014). The exchange of PHE and TYR between extracellular and intracellular pools was described and the hydroxylation of PHE to TYR was estimated. In addition, the extraction of amino acids from the liver via the portal vein and hepatic artery pools was represented. Upon application to dairy cattle during infusion of $\left[1-{ }^{13} \mathrm{C}\right]$ phenylalanine and $\left[2,3,5,6-{ }^{2} \mathrm{H}\right]$ tyrosine tracers, the model was shown to be effective in providing information about the fates of PHE and TYR in the liver, and could 
382 be used as part of a more complex system describing amino acid metabolism in the whole 383 animal.

Just as accurate measurements of precursor pool enrichment are critical for the use of

385 labelled amino acids to determine tissue protein synthesis generally, the measurement of

386 intracellular free PHE and TYR enrichment are crucial components of the present model, yet

387 had to be estimated along with liver export protein in order to apply the model using the data

388 available from the experiment. If the model is to be applied more rigorously, future in vivo

389 studies should measure simultaneously the intracellular free PHE and TYR pools and liver

390 export protein, along with the plasma enrichments and flow rates measured in the present

391 work. Furthermore, the model could not be solved by algebraic means alone, as initially it

392 solved to give non-physiological flows and had to be re-solved by adjusting selected

393 enrichments using a least-squares minimisation routine. Therefore, the mathematical exercise

394 of cleaving the combined model and solving the PHE and TYR sub-models independently

395 but sequentially merits future investigation.

396 
This work was funded, in part, through DEFRA project LS3656, the European Union FP-7

REDNEX Project and the Canada Research Chairs Program. The experimental work was

funded by a consortium of DEFRA, BBSRC, the Milk Development Council, Purina Mills

401 LLC, and NUTRECO Inc.

402

403

\section{References}

404 Berthiaume, R., Thivierge, M.C., Patton, R.A., Dubreuil, P., Stevenson, M., McBride, B.W., 405 Lapierre, H., 2006. Effect of ruminally protected methionine on splanchnic metabolism of amino acids in lactating dairy cows. J. Dairy Sci. 89, 1621-1634.

Cantalapiedra-Hijar, G., Lemosquet, S., Rodriguez-Lopez, J.M., Messad, F., Ortigues-Marty, 408 I., 2014. Diets rich in starch increase the posthepatic availability of amino acids in dairy cows fed diets at low and normal protein levels. J. Dairy Sci. 97, 5151-5166.

410

Connell, A., Calder, A.G., Anderson, S.E., Lobley, G.E., 1997. Hepatic protein synthesis in the sheep: effect of intake as monitored by use of stable-isotope-labelled glycine, leucine and phenylalanine. Br. J. Nutr. 77,255-271.

413 Crompton, L.A., France, J., Reynolds, C.K., Mills, J.A.N., Hanigan, M.D., Ellis, J.L., 414 Bannink, A., Bequette, B.J., Dijkstra, J., 2014. An isotope dilution model for partitioning 415 phenylalanine and tyrosine uptake by the mammary gland of lactating dairy cows. J. 416 Theor. Biol. 359, 54-60.

417 Dijkstra, J., Oenema, O., Van Groenigen, J.W., Spek, J.W., van Vuuren, A.M., Bannink, A., 418 2013. Diet effects on urine composition of cattle and $\mathrm{N}_{2} \mathrm{O}$ emissions. Animal 7 (suppl. 2), 419 292-302. 

amino acid infusions stimulate mammary expression of eukaryotic initiation factor $2 \mathrm{~B} \varepsilon$ but milk protein yield is not increased during an imbalance. J. Dairy Sci. 98:4499-4508.

Doepel, L., Hewage, I.I., Lapierre, H., 2016. Milk protein yield and mammary metabolism are affected by phenylalanine deficiency but not by threonine or tryptophan deficiency. J. Dairy Sci. 99, 3144-3156.

France, J., Hanigan, M.D., Reynolds C.K., Dijkstra J., Crompton, L.A., Maas J.A., Bequette, B.J., Metcalf J.A., Lobley, G.E., MacRae, J.C., Beever, D.E., 1998. An isotope dilution model for partitioning leucine uptake by the bovine liver. J. Theor. Biol. 198, 121-133.

Harris, P.A., Skene, P.A., Buchan, V., Milne, E., Calder, A.G., Anderson, S.E., Connell, A, Lobley, G.E., 1992. Effect of food intake on hind-limb and whole-body protein metabolism in young growing sheep: chronic studies based on arterio-venous techniques. Br. J. Nutr. 68, 389-407.

Hristov, A.N., Price, W.J., Shafii, B., 2004. A meta-analysis examining the relationship among dietary factors, dry matter intake, and milk and milk protein yield in dairy cows. J. Dairy Sci. 87, 2184-2196.

Katz, M.L., Bergman, E.N., 1969. Simultaneous measurements of hepatic and portal venous blood flow in the sheep and dog. Am. J. Physiol. 216, 946-952.

Larsen, M., Galindo, C., Ouellet, D.R., Maxin, G., Kristensen, N.B., Lapierre, H., 2015. Abomasal amino acid infusion in postpartum dairy cows: Effect on whole-body,

441 Matthews, D.E., 2007. An overview of phenylalanine and tyrosine kinetics in humans. J. Nutr. 137, 1549S-1555S. vivo regulation of phenylalanine hydroxylation to tyrosine, studied using enrichment in 
apoB-100 In vivo regulation of phenylalanine hydroxylation to tyrosine, studied using enrichment in apoB-100. Am J Physiol Endocrinol Metab, 294(2), E475-E479.

Raggio, G., Lobley, G.E., Berthiaume, R., Pellerin, D., Allard, G., Dubreuil, P., Lapierre, H., 2007. Effect of protein supply on hepatic synthesis of plasma and constitutive proteins in lactating dairy cows. J. Dairy Sci. 90, 352-359.

Reynolds, C.K., 2006. Splanchnic metabolism of amino acids in ruminants, in: Sejrsen, K., Hvelplund, T., Nielsen, M.O., (Eds), Ruminant Physiology: Digestion, metabolism and impact of nutrition on gene expression, immunology and stress. Wageningen Academic Press, Wageningen, the Netherlands, pp. 225-248.

Rulquin, H., Pisulewski, P., 2000. Effects of duodenal infusions of graded amounts of Phe on mammary uptake and metabolism in dairy cows. J. Dairy Sci. 83(Suppl. 1), 267-268.

Tagari, H., Webb Jr., K., Theurer, B., Huber, T., DeYoung, D., Cuneo, P., Santos, J.E.P., Simas, J., Sadik, M., Alio, A., Lozano, O., Delgado-Elorduy, A., Nussio, L., Nussio, C., Santos, F., 2004. Portal drained visceral flux, hepatic metabolism, and mammary uptake of free and peptide-bound amino acids and milk amino acid output in dairy cows fed diets

Tagari, H., Webb Jr., K., Theurer, B., Huber, T., DeYoung, D., Cuneo, P., Santos, J.E.P., Simas, J., Sadik, M., Alio, A., Lozano, O., Delgado-Elorduy, A., Nussio, L., Bittar, C.M.M., Santos, F., 2008. Mammary uptake, portal-drained visceral flux, and hepatic metabolism of free and peptide-bound amino acids in cows fed steam-flaked or dry-rolled sorghum grain diets. J. Dairy Sci. 91, 679-697.

UniProt Consortium, 2017. UniProt: the universal protein knowledgebase. Nucleic Acids Res. 45, D158-D169.

Waterlow, J.C. 2006. Protein turnover. CAB International, Wallingford, UK. 
471 Table 1. Principle symbols used for the kinetic model.

\begin{tabular}{|c|c|c|}
\hline$F_{i j}$ & $\begin{array}{l}\text { Flow of } \mathrm{PHE}^{\mathrm{a}} \text { or TYR } \mathrm{TY}^{\mathrm{a}} \text { to pool } i \text { from } j ; F_{i 0} \text { denotes an } \\
\text { external flow into pool } i \text { and } F_{0 j} \text { denotes a flow from } \\
\text { pool } j \text { out of the system }\end{array}$ & $\mu \mathrm{mol} / \mathrm{min}$ \\
\hline$I_{i}$ & $\begin{array}{l}\text { Effective rate of constant infusion of }{ }^{13} \mathrm{C} \text { labelled PHE } \\
\text { or TYR into primary pool } i\end{array}$ & $\mu \mathrm{mol} / \mathrm{min}$ \\
\hline$\Phi_{i}$ & $\begin{array}{l}\text { Effective rate of constant infusion of }{ }^{2} \mathrm{H} \text { labelled TYR } \\
\text { into primary pool } i\end{array}$ & $\mu \mathrm{mol} / \mathrm{min}$ \\
\hline$Q_{i}$ & Quantity of PHE ${ }^{\mathrm{a}}$ or TYR ${ }^{\mathrm{a}}$ in pool $i$ & $\mu \mathrm{mol}$ \\
\hline$q_{i}$ & Quantity of ${ }^{13} \mathrm{C}$ labelled PHE or TYR in pool $i$ & $\mu \mathrm{mol}$ \\
\hline$\phi_{i}$ & Quantity of ${ }^{2} \mathrm{H}$ labelled TYR in pool $i$ & $\mu \mathrm{mol}$ \\
\hline$e_{i}$ & Enrichment of ${ }^{13} \mathrm{C}$ PHE or TYR in pool $i:\left(=q_{i} / Q_{i}\right)$ & atoms $\%$ excess $/ \mu \mathrm{mol}$ \\
\hline$\varepsilon_{i}$ & Enrichment of ${ }^{2} \mathrm{H}$ TYR in pool $i:\left(=\phi_{i} / Q_{i}\right)$ & atoms $\%$ excess $/ \mu \mathrm{mol}$ \\
\hline$t$ & Time & $\min$ \\
\hline
\end{tabular}

472

473

${ }^{\mathrm{a}}$ Total material (i.e. tracee + tracer).

474 
Table 2. Experimental and other inputs.

476

\begin{tabular}{|c|c|c|c|c|c|}
\hline Cow & & $323 / 14$ & $341 / 29$ & $6031 / 42$ & $6132 / 43^{a}$ \\
\hline Dietary CP (g/kg) & & 175 & 128 & 128 & 175 \\
\hline Milk yield (kg/d) & & 25.8 & 24.1 & 24.2 & 25.3 \\
\hline Plateau & $e_{1}$ & 2.19 & 3.37 & 2.79 & 2.10 \\
\hline \multirow[t]{11}{*}{ enrichment (APE) } & $e_{2}$ & 3.58 & 5.51 & 4.31 & 3.32 \\
\hline & $e_{3}^{b}$ & 0.15 & 0.18 & 0.18 & 0.32 \\
\hline & $e_{4}^{\mathrm{b}}$ & 0.28 & 0.30 & 0.30 & 0.43 \\
\hline & $e_{6}{ }^{b}$ & 1.07 & 1.65 & 1.29 & 1.00 \\
\hline & $e_{7}^{\mathrm{b}}$ & 0.08 & 0.09 & 0.09 & 0.13 \\
\hline & $e_{9}$ & 2.14 & 3.54 & 2.70 & 2.00 \\
\hline & $e_{\mathrm{X}}^{\mathrm{b}}$ & 0.25 & 0.32 & 0.28 & 0.39 \\
\hline & $\varepsilon_{3}$ & 0.76 & 1.16 & 0.85 & 0.79 \\
\hline & $\varepsilon_{4}$ & 1.12 & 1.97 & 1.21 & 1.15 \\
\hline & $\varepsilon_{7}^{\mathrm{b}}$ & 0.34 & 0.59 & 0.36 & 0.35 \\
\hline & $\varepsilon_{\mathrm{X}}$ & 0.73 & 1.23 & 0.83 & 0.74 \\
\hline \multirow[t]{9}{*}{ Flow $(\mu \mathrm{mol} / \mathrm{min})$} & $I_{1}$ & 52.6 & 44.5 & 53.7 & 56.9 \\
\hline & $I_{2}$ & 24.2 & 36.6 & 16.5 & 9.55 \\
\hline & $\Phi_{3}$ & 19.0 & 12.2 & 16.5 & 16.3 \\
\hline & $\Phi_{4}$ & 8.49 & 10.4 & 4.99 & 2.72 \\
\hline & $F_{05}$ & 33.8 & 33.8 & 33.8 & 33.8 \\
\hline & $F_{07}^{(o)}$ & 211 & 146 & 351 & 525 \\
\hline & $F_{08}$ & 25.0 & 25.0 & 25.0 & 25.0 \\
\hline & $F_{09}$ & 2595 & 1777 & 1938 & 2473 \\
\hline & $F_{0 X}$ & 2858 & 1399 & 2034 & 2012 \\
\hline
\end{tabular}

${ }^{\mathrm{a}}$ Essential amino acid infusion

$479{ }^{\mathrm{b}}$ Initial value 
Table 3. Phenylalanine and tyrosine uptake and partition by the liver for four lactating dairy cows obtained using the ten-pool model (symbols are defined in the text and Table 1).

\begin{tabular}{|c|c|c|c|c|c|}
\hline Cow & & $323 / 14$ & $341 / 29$ & $6031 / 42$ & $6132 / 43$ \\
\hline \multirow[t]{21}{*}{ Flow $(\mu \mathrm{mol} / \mathrm{min})$} & $F_{10}$ & 2403 & 1319 & 1921 & 2711 \\
\hline & $F_{20}$ & 676 & 665 & 382 & 288 \\
\hline & $F_{30}$ & 2486 & 1048 & 1951 & 2072 \\
\hline & $F_{40}$ & 756 & 530 & 414 & 237 \\
\hline & $\overline{F_{56}-F_{65}}$ & 33.8 & 33.8 & 33.8 & 33.8 \\
\hline & $\overline{F_{87}-F_{78}}$ & 25.0 & 25.0 & 25.0 & 25.0 \\
\hline & $F_{\mathrm{X} 7}$ & 547 & 308 & 215 & 300 \\
\hline & $F_{\mathrm{X} 4}$ & 534 & 412 & 287 & 187 \\
\hline & $F_{\mathrm{X} 3}$ & 1778 & 679 & 1532 & 1525 \\
\hline & $F_{73}$ & 708 & 369 & 419 & 547 \\
\hline & $F_{74}$ & 223 & 118 & 127 & 50 \\
\hline & $F_{07}^{(s)}$ & 2323 & 1225 & 1713 & 1476 \\
\hline & $F_{76}$ & 138 & 70 & 172 & 332 \\
\hline & $F_{70}$ & 2037 & 1147 & 1586 & 1397 \\
\hline & $F_{91}$ & 1597 & 967 & 1366 & 1935 \\
\hline & $F_{92}$ & 449 & 487 & 272 & 205 \\
\hline & $F_{96}$ & 548 & 323 & 300 & 333 \\
\hline & $F_{61}$ & 806 & 353 & 555 & 776 \\
\hline & $F_{62}$ & 227 & 178 & 110 & 82 \\
\hline & $F_{06}$ & 2455 & 1568 & 2071 & 2444 \\
\hline & $F_{60}$ & 2143 & 1465 & 1911 & 2284 \\
\hline Adjusted & $e_{3}{ }^{\mathrm{a}}$ & 0.19 & 0.19 & 0.16 & 0.25 \\
\hline plateau & $e_{4}^{\mathrm{a}}$ & 0.32 & 0.38 & 0.35 & 0.54 \\
\hline \multirow[t]{4}{*}{ enrichment (APE) } & $e_{6}{ }^{\mathrm{a}}$ & 0.81 & 1.09 & 0.79 & 0.61 \\
\hline & $e_{7}^{\mathrm{a}}$ & 0.10 & 0.11 & 0.11 & 0.16 \\
\hline & $e_{\mathrm{X}}^{\mathrm{a}}$ & 0.20 & 0.23 & 0.18 & 0.26 \\
\hline & $\varepsilon_{7}{ }^{\mathrm{a}}$ & 0.25 & 0.39 & 0.22 & 0.21 \\
\hline
\end{tabular}

${ }^{\mathrm{a}}$ Final value 
88 Table 4. Average slope (\%) for each of the flows calculated by the model obtained by perturbing each input in turn ${ }^{\mathrm{a}}$.

\begin{tabular}{|c|c|c|c|c|c|c|c|c|c|c|c|c|c|c|c|c|c|c|c|c|c|c|}
\hline \multirow[t]{2}{*}{ Flow } & \multirow{2}{*}{$\begin{array}{l}\text { Unperturbed } \\
(\mu \mathrm{mol} / \mathrm{min})^{\mathrm{b}}\end{array}$} & \multicolumn{21}{|c|}{ Input perturbed $^{\mathrm{c}}$} \\
\hline & & $e_{1}$ & $e_{2}$ & $e_{3}$ & $e_{4}$ & $e_{6}$ & $e_{7}$ & $e_{9}$ & $e_{\mathrm{X}}$ & $\varepsilon_{3}$ & $\varepsilon_{4}$ & $\varepsilon_{7}$ & $\varepsilon_{\mathrm{X}}$ & $I_{1}$ & $I_{2}$ & $\Phi_{3}$ & $\Phi_{4}$ & $F_{05}$ & $F_{07}^{(o)}$ & $F_{08}$ & $F_{09}$ & $F_{0 \mathrm{X}}$ \\
\hline$\overline{F_{10}}$ & 2086 & & & & & & & & & & & & & 1.0 & & & & & & & & \\
\hline$F_{20}$ & 547 & & & & & & & & & & & & & & 1.0 & & & & & & & \\
\hline$F_{30}$ & 1862 & & & & & & & & & & & & & & & 1.0 & & & & & & \\
\hline$F_{40}$ & 519 & & & & & & & & & & & & & & & & 1.0 & & & & & \\
\hline$\overline{F_{56}-F_{65}}$ & 34 & & & & & & & & & & & & & & & & & 1.0 & & & & \\
\hline$\overline{F_{87}-F_{78}}$ & 25 & & & & & & & & & & & & & & & & & & & 1.0 & & \\
\hline$F_{\mathrm{X} 7}$ & 260 & & & -7.6 & -3.4 & & -0.64 & & 9.2 & 16 & 3.8 & 0.62 & -16 & & & & & & & & & 1.0 \\
\hline$F_{\mathrm{X} 4}$ & 309 & & & -8.5 & -3.8 & & -0.71 & & 10 & 5.2 & 1.2 & 0.20 & -5.2 & & & & & & & & & 1.0 \\
\hline$F_{\mathrm{X} 3}$ & 1522 & & & 3.0 & 1.4 & & 0.25 & & -3.7 & -3.8 & -0.91 & -0.15 & 3.8 & & & & & & & & & 1.0 \\
\hline$F_{73}$ & 341 & & & -13 & -6.1 & & -1.1 & & 16 & 17 & 4.1 & 0.65 & -17 & & & 5.5 & & & & & & -4.5 \\
\hline$F_{74}$ & 210 & & & 12 & 5.6 & & 1.0 & & -15 & -7.7 & -1.8 & -0.29 & 7.6 & & & & 2.5 & & & & & -1.5 \\
\hline$F_{07}^{(s)}$ & 1626 & & & & & & & 0.18 & & 3.8 & 1.6 & -1.2 & -4.2 & & & 3.8 & 1.6 & & -0.18 & -0.02 & & -4.2 \\
\hline$F_{76}$ & 136 & & & -3.3 & -1.9 & -1.0 & 2.1 & & 4.1 & 6.6 & 2.8 & -2.1 & -7.4 & & & 3.3 & 1.0 & & & & & -3.3 \\
\hline$F_{70}$ & 1512 & & & 0.30 & 0.17 & 0.09 & -0.19 & & -0.37 & 3.5 & 1.5 & -1.1 & -3.9 & & & 2.6 & 1.3 & & & & & -2.9 \\
\hline$F_{91}$ & 1488 & -1.0 & -0.41 & & & -0.08 & & 1.5 & & & & & & 0.33 & -0.33 & & & & & & 1.0 & \\
\hline$F_{92}$ & 391 & -1.0 & -0.41 & & & -0.08 & & 1.5 & & & & & & -0.68 & 0.67 & & & & & & 1.0 & \\
\hline$F_{96}$ & 366 & 5.2 & 2.1 & & & 0.39 & & -7.5 & & & & & & -0.64 & 0.63 & & & & & & 1.0 & \\
\hline$F_{61}$ & 598 & 2.5 & 1.0 & & & 0.19 & & -3.6 & & & & & & 2.7 & 0.82 & & & & & & -2.5 & \\
\hline$F_{62}$ & 157 & 2.5 & 1.0 & & & 0.19 & & -3.6 & & & & & & 1.7 & 1.8 & & & & & & -2.5 & \\
\hline$F_{06}$ & 2163 & 3.1 & 1.3 & 0.21 & 0.12 & -1.1 & -0.13 & -3.3 & -0.26 & -0.42 & -0.18 & 0.14 & 0.46 & 3.1 & 1.3 & -0.21 & -0.06 & -0.02 & & & -3.3 & 0.21 \\
\hline$F_{60}$ & 1944 & 3.4 & 1.4 & & & -1.2 & & -3.6 & & & & & & 2.3 & 1.2 & & & & & & -2.5 & \\
\hline
\end{tabular}

${ }^{\mathrm{a}}$ The slope for each flow is expressed relative to the value of the flow obtained when no perturbation is made. Only slopes which differ from zero are shown.

${ }^{\mathrm{b}}$ Values calculated from the mean of inputs reported in Table 2.

${ }^{\mathrm{c}}$ Model solved by perturbing each input in turn by $0 \%, \pm 10 \%$ and $\pm 20 \%$. 
Figure 1. Scheme for the uptake and utilisation of PHE and TYR by the liver of lactating dairy cows: (a) total PHE and TYR, (b) $\left[{ }^{13} \mathrm{C}\right]$ labelled PHE and TYR and (c) $\left[{ }^{2} \mathrm{H}\right]$ labelled TYR. Nomenclature is defined in Table 1. Represented pools are numbered 1 to X and labelled in Figure

496 1a. The small circles in Figure 1a indicate flows out of the system which need to be measured experimentally.

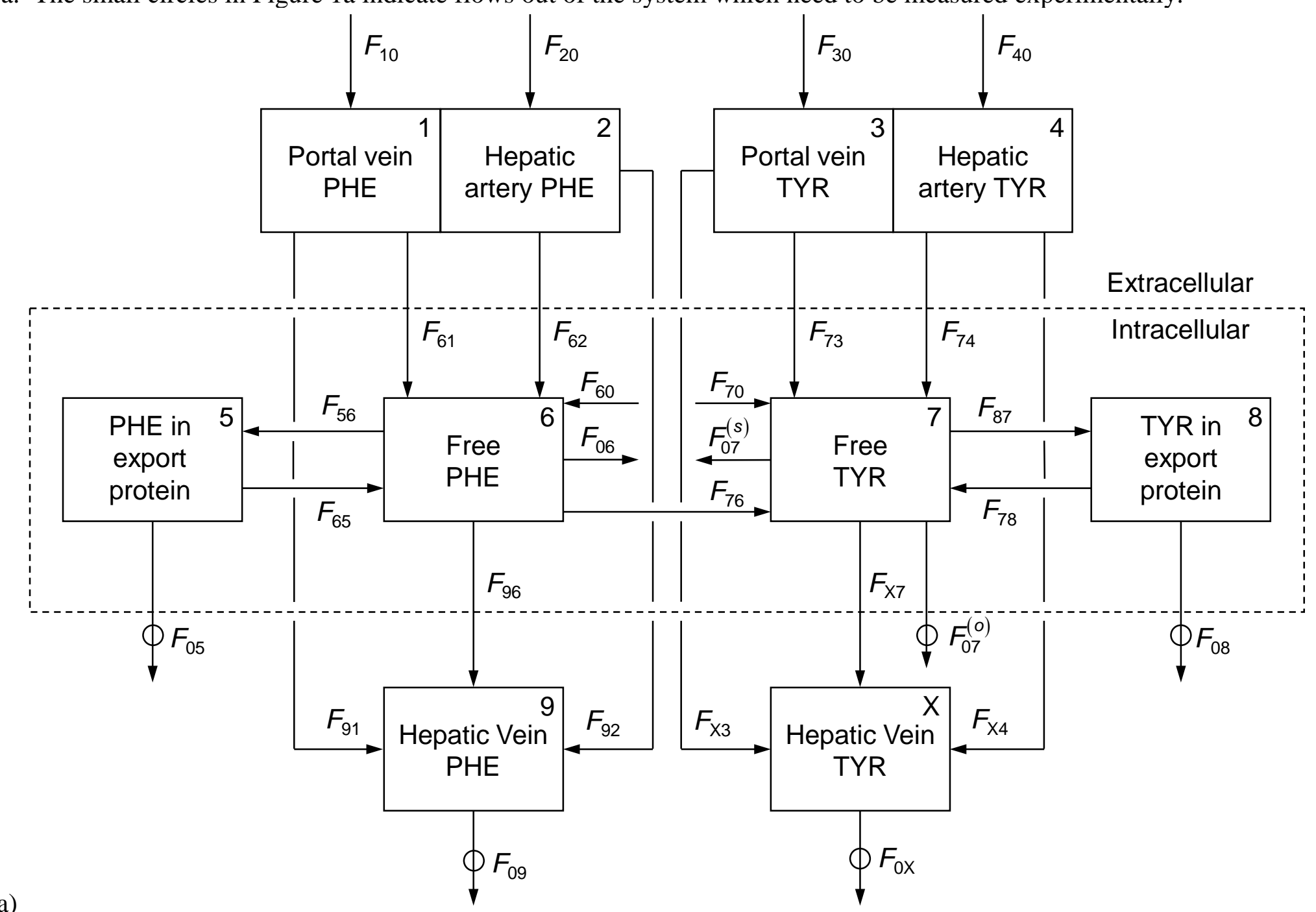




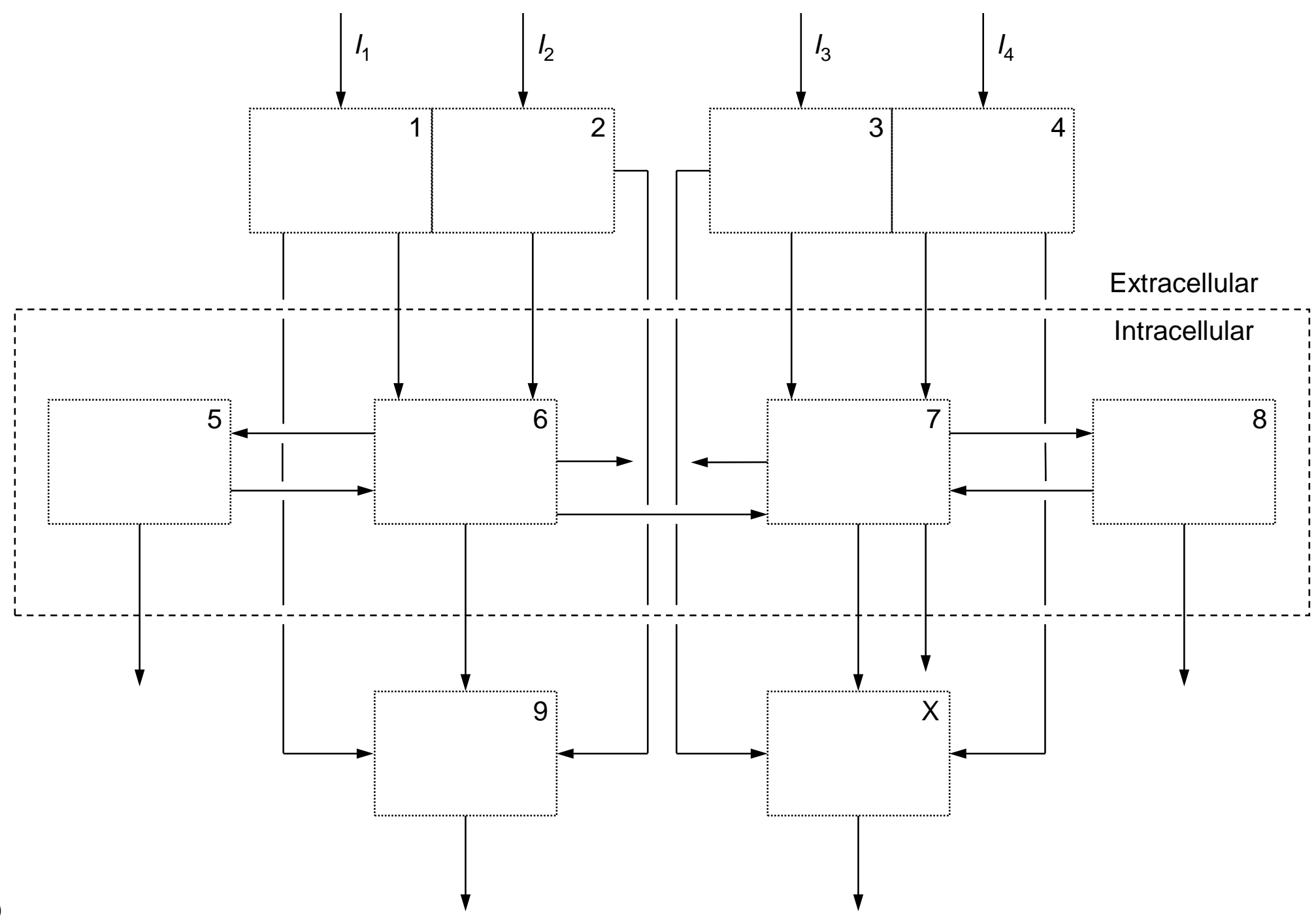




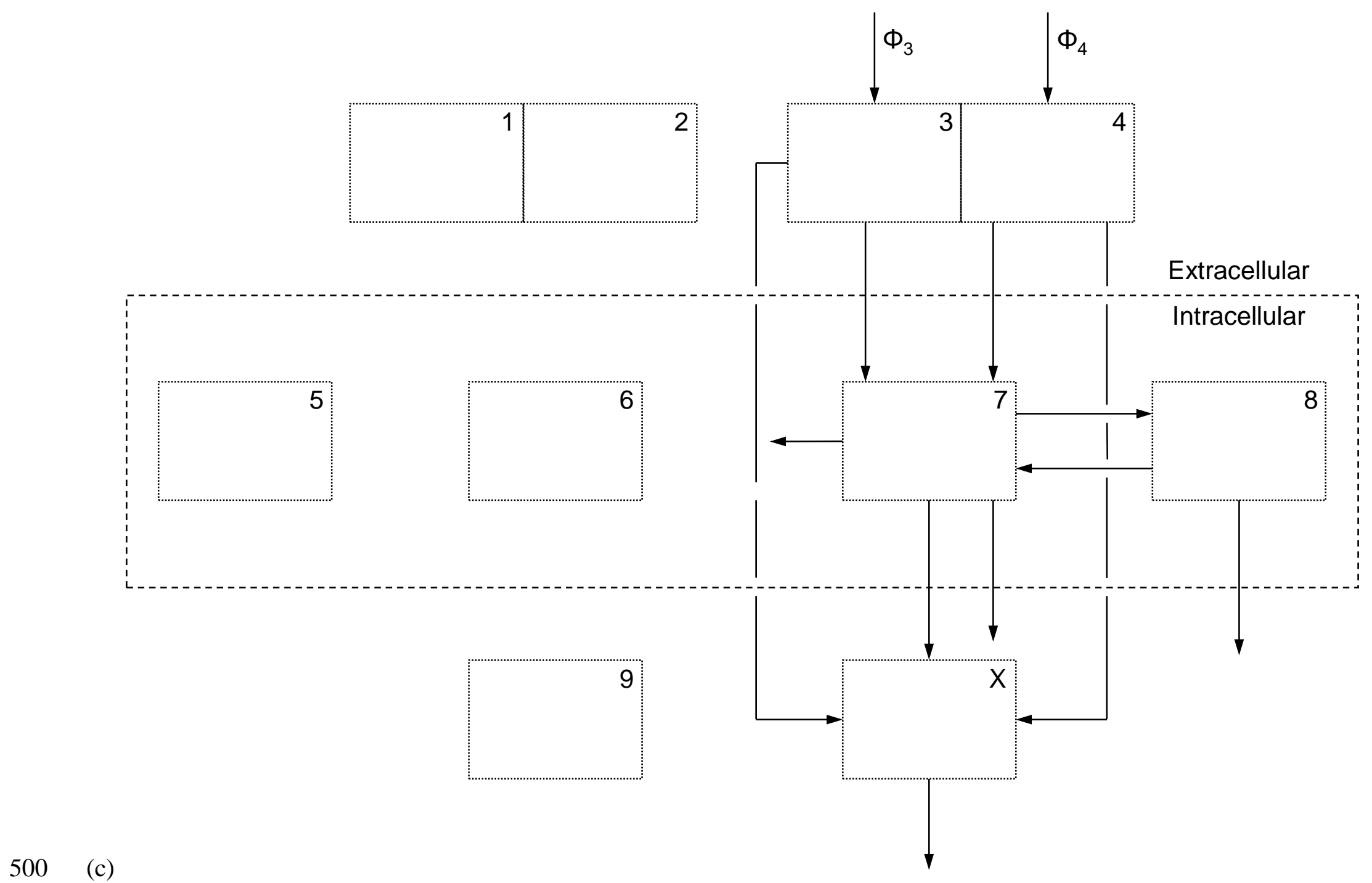

